\title{
Research Paper: Development and Validation of $\gtrsim$ (L) Emotion Regulation Strategies in Germophobia Questionnaire in Iran
}

\author{
Seyed Mohammad Reza Alavizadeh ${ }^{*}$ (D), Mojgan Sepahmansour ${ }^{2}$ (D), Somaye Entezari ${ }^{3}$ (D), Mohammadreza Seirafi ${ }^{4}$ (D) Mehrdad Sabet $^{5}$ (i)
}

1. Department of Psychology, School of Humanity Sciences, East Tehran Branch, Islamic Azad University, Tehran, Iran.

2. Department of Psychology, School of Psychology and Educational Sciences, Central Tehran Branch, Islamic Azad University, Tehran, Iran.

3. Department of Psychology, School of Humanity Sciences, Shahrood Branch, Islamic Azad University, Shahrood, Iran.

4. Department of Psychology, School of Psychology, Karaj Branch, Islamic Azad University, Karaj, Iran.

5. Department of Psychology, School of Psychology and Social Sciences, Roudehen Branch, Islamic Azad University, Roudehen, Iran.

\begin{tabular}{|c|c|}
\hline & \\
\hline 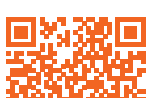 & $\begin{array}{l}\text { tion of Emotion Regulation Strategies in Germophobia Questionnaire in Iran. Journal of Practice in Clinical Psychology, 8(4), } \\
\text { 307-316. https://doi.org/10.32598/jpcp.8.4.695.1 }\end{array}$ \\
\hline 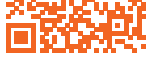 & doi https://doi.org/10.32598/jpcp.8.4.695.1 \\
\hline
\end{tabular}

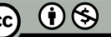

Article info:

Received: 20 Apr 2020

Accepted: 27 Aug 2020

Available Online: 01 Oct 2020

Keywords:

Psychometric properties, Validity, Reliability, Emotion regulation strategies,

Germophobia, Phobic Disorders, COVID-19

\section{ABSTRACT}

Objective: The Coronavirus Disease-2019 (COVID-19) has recently been identified as a pandemic by the World Health Organization. The outbreak of the disease has caused numerous individuals around the world to become extremely frightened and subsequently present the signs of phobia. Fear is the basic emotion of anxiety disorders and individuals cope with their emotions by different strategies. The present study aimed at developing and validating Emotion Regulation Strategies for Germophobia Questionnaire (ERS-GPQ).

Methods: The study participants were 99 individuals ( 74 females) of the Iranian population with concerns about germs who were selected with the snowball sampling method. They completed the ERS-GPQ and GPQ in the Google Forms platform.

Results: The present study results illustrated that the ERS-GPQ has acceptable internal consistency with Cronbach's alpha coefficient $(\mathrm{a}=0.61)$, reliability coefficients with split-half (0.70), and one-week test-retest (0.92); the ERS-GPQ also presented a moderate positive correlation with the contamination obsessions checklist of GPQ $(r=0.44)$ as the convergent coefficient. Besides, the confirmatory factor analysis indicated 2 factors of the ERS-GPQ. Finally, the ERS-GPQ has 2 components with good convergent and discriminate validities and composite reliability.

Conclusion: Based on the current research findings, the ERS-GPQ has acceptable and good psychometric properties; researchers can use the ERS-GPQ as a reliable and valid instrument for assessing ER strategies concerning germophobia. Furthermore, it has some considerations for practitioners in epidemic and pandemic crises, like COVID-19.

\section{* Corresponding Author:}

Seyed Mohammad Reza Alavizadeh, PhD.

Address: Department of Psychology, School of Humanity Sciences, East Tehran Branch, Islamic Azad University, Tehran, Iran.

Tel: +98 (912) 3667765

E-mail:alavizadehsmr@gmail.com 


\section{Highlights}

- ERS-GPQ has acceptable and good psychometric properties.

- Adaptive emotion-regulation strategies include problem solving, reappraisal, and acceptance.

- Maladaptive emotion-regulation strategies include denial, behavioral avoidance, rumination, thought suppression

\section{Plain Language Summary}

We aimed to develop and evaluate the psychometric properties of the Emotion Regulation Strategies for Germophobia Questionnaire (ERS-GPQ) in Iran. According to the Confirmatory factor analyses and goodness of fit indexes, the ERS-GPQ illustrate acceptable validity and reliability. The ERS-GPQ is a adequate measure for the specific assessment of the emotion regulation strategies for germophobia during pandemic of COVID-19 in the Iran.

\section{Introduction}

he Coronavirus Disease-2019 (COVID-19) has recently been identified as a pandemic by the World Health Organization (World Health Organization, 2020). The outbreak of COVID-19 has caused numerous individuals around the world to become extreme-

ly frightened and present signs of phobia (Alavizadeh Sepahmansour, Entezari, Seirafi, \& Sabet, 2020). Fear is the basic emotion of anxiety disorders and individuals cope with their emotions by different strategies. These copping styles are also called Emotion Regulation Strategies (ERS) (Lotfi, Bakhtiyari, Asgharnezhad Farid, \& Amini, 2013). It is assumed that several individual ERSs can be risk factors or protective factors for psychopathology (Aldao, Nolen-Hoeksema, \& Schweizer, 2010).

Various ERSs are introduced (Bhatnagar, Shukla, \& Pandey, 2020; Gao, Liu, \& Ullah, 2019), i.e. linked to maladaptive behaviors, such as eating disorders, selfinflicted injury, substance abuse (Darvish Molla, Shirazi, \& Nikmanesh, 2018), and emotional disorders. However, a challenge about ER is developing a conceptual framework that helps to organize multiple ER forms. The modal model of emotion (Gross \& Thompson, 2007), proposes an approach to the consequences of procedures involved in identified ERSs, each of which can be targeted by ER. In the modal model of ER, there exist 5 strategies that every individual can use to adjust and regulate their emotions. These 5 strategies represent 5 common traits of the ER process, as follows: situation selection; situation modification; attentional deployment; cognitive change, and response modulation (Gross, 1998). These 5 points vary in the process of creating emotions with different substantive effects. These 5 strategies attempt to cover the styles offered by researchers. These 5 strategies have been cited as a framework for various point-and-click strategies that can be used in practice.

In social and practical contexts, the process model of emotions divide ERSs as adaptive and maladaptive approaches; adaptive manners include expressing emotions with appropriate consequences (Thompson, 1994). Furthermore, maladaptive methods are expressing emotions with unsuitable consequences. Adaptive ways include problem-solving, reappraisal, and acceptance that have been protective against emotional disorders; maladaptive styles include thought suppression, psychological avoidance, rumination, behavioral avoidance (Aldao et al., 2010; Hong et al., 2018; Schäfer, Naumann, Holmes, Tuschen-Caffier, \& Samson, 2017), denial, and the ultimate ERS is trust.

Problem-solving can be identified as an ERS that includes cognitive and behavioral responses aimed at changing by alternative undesirable conditions that cause unpleasant emotions (Schäfer et al., 2017). Acceptance is defined as being experientially open to the reality of the present moment rather than being in a state of either belief or disbelief or judging what is fair or unfair (Roemer \& Orsillo, 2002). Reappraisal includes the creation of agreeable or positive explanations or viewpoints of distressing situations as a manner for stress reduction (Aldao et al., 2010).

Rumination is defined as a responding form to a stressful condition that includes passive and repetitive attention to the negative aspects of activated events and consequences of the situation (Nolen-Hoeksema, Wisco, \& Lyubomirsky, 2008). Thought suppression reflects inhibiting thoughts, i.e. linked to emotions (Hong et al., 2018). Behavioral avoid- 
ance is identified as completed behavioral inhibition and avoidance in outer conditions or against external stimuli (Fairholme, Boisseau, Ellard, Ehrenreich, \& Barlow, 2010). Denial is a defense mechanism (Garg, 2017); however, it is also categorized as an ERS if a person consciously denies stressful situations.

Numerous scientists suggested that the biopsychosocial model can be developed to involve the spiritual component, as well (Saad, de Medeiros, \& Mosini, 2017; World Health Organization, 1999); for religious individuals, trust indicates hoping that what they want to happen will happen by the God wills or sanctities and it helps them to reduce their emotional distresses.

This article was a part of a comprehensive study about germophobia in the COVID-19 pandemic. Based on Google Scholar, no instrument is available for assessing germophobia and ERSs for germophobia. Developing a new assessment tool can help mental health practitioners in assessing the ERSs for germophobia in individuals encountering germophobic problems, especially during pandemics, like the recent COVID-19. The present study aimed to develop and validate a questionnaire for ERSs about germophobia in an Iranian sample.

\section{Methods}

The present descriptive study aimed to investigate the psychometric properties and validate an instrument used in clinical psychology. The statistical population of this study included all Iranian individuals with concerns about germs.

The study participants were 99 Iranian individuals concerned about germs. The minimum sample size necessary to detect minimum $\mathrm{R}^{2}$ values of 0.10 ; in any of the two constructs in the structural model for significance levels of 5\%; assuming the commonly used level of statistical power of $80 \%$, and a specific level of complexity of the partial least squares path mode is equal to 90 (Hair, Hult, Ringle, \& Sarstedt, 2017). In this study, $\mathrm{R}^{2}$ for each component was $>0.90$, suggesting that smaller sample size could be used in this study. The study participants were selected by the snowball sampling approach. Accordingly, they completed the relevant questionnaires through the internet in the Google Forms platform. All study participants re-completed the questionnaires after a week, as a retest assessment. At the introduction of the employed form, all research participants were advised about the ethical codes, like the privacy policy, the right to discontinue participating in the research before completing and submitting the questionnaires, and that they could be informed about their results.
The items of the Emotion Regulation Strategies for Germophobia Questionnaire (ERS-GPQ) include 15 items answered on a 5-point Likert-type scale (ranging from 1: strongly disagree to 5: strongly agree). This questionnaire was generated based on emotional processing theory (Gross \& Thompson, 2007). In total, 6 items belong to aERS component, 8 items concern mERS, and 1 question probes trust, as an added spiritual component.

Germophobia Questionnaire (GPQ): The items of GPQ were designed based on the metacognitive therapy theory (Wells, 2009), and the metacognitive beliefs questionnaire, i.e. developed by Wells and Cartwright-Hatton (2004). Accordingly, the positive and negative metacognition associated with the germs were identified by an interview with an individual experiencing the spectrum of germophobia, with a total of 5 questions assigned to each component. The study participants answered 10 questions on a 5-point Likert-type scale, ranging from 1 (strongly disagree) to 5 (strongly agree). The questionnaire has acceptable reliability and validity (Alavizadeh et al., 2020).

The Yale-Brown Obsessive Compulsive Scale (YBOCS): Applied as a specific measure of assessing the severity of Obsessive-Compulsive Disorder (OCD), was developed by Goodman et al. (1989). This scale is also answered on a 5-point Likert-type scale. The Y-BOCS is a multicultural measure, i.e. validated in various countries (López-Pina et al., 2015), including Iran (Rajezi Esfahani, Motaghipour, Kamkari, Zahiredin, \& Janbozorgi, 2012), Japan (Ishikawa, Kobori, \& Shimizu, 2014), and Italy (Melli et al., 2015). The Persian version of Y-BOCS has the optimal level of internal consistency, split-half reliability, and test-retest reliability (Rajezi Esfahani et al., 2012). The mean reliability value of the Y-BOCS in a meta-analysis study was measured as 0.8 (López-Pina et al., 2015). Its Persian version contains the obsessions checklist of Y-BOCS, i.e. a possible related structure to germophobia was selected to be studied.

The obtained data were analyzed using descriptive statistics, such as frequency, percentage, minimum and maximum, mean, standard deviation, skewness, and kurtosis, as well as inferential statistics, including t-test, and one-way Analysis of Variance (ANOVA). Eventually, we explored the relevant psychometric properties by internal consistency, split-half, and test-retest reliability coefficients, deferential concurrent validity, and confirmatory factor analysis method as a Partial Least Squares Structural Equation Modeling (PLS-SEM). The data were analyzed in SPSS and SmartPLS software. 


\section{Results}

The demographic findings and data on the comparison of germophobia based on the subscales of gender, educational level, marital status, and infection diseases history are illustrated in Table 1.
The t-test results demonstrated significant differences between men (Mean $\pm \mathrm{SD}=22.38 \pm 3.26)$ and women (Mean $\pm \mathrm{SD}=24.19 \pm 2.42$ ) in adaptive ERS-GPQ ( $\mathrm{t}=2.97$, $\mathrm{df}=97, \mathrm{P}=0.01$ ); however, there were no differences in adaptive and maladaptive ERS-GPQ among educational level $(\mathrm{fmERS}=0.78, \mathrm{df}=4,94, \mathrm{P}=0.54$; faERS $=0.69$, $\mathrm{df}=4,94, \mathrm{P}=0.60)$, marital status $(\mathrm{fmERS}=2.37, \mathrm{df}=4,95$,

Table 1. Demographic findings, and comparing germophobia subscales' data

\begin{tabular}{|c|c|c|c|c|c|c|}
\hline Scales & Subscale & No. (\%) & Cumulative Percentage & $t / f$ & df & $\mathbf{P}$ \\
\hline \multirow{2}{*}{ Gender } & Female & $73(74)$ & 74 & 2.97 & 97 & 0.01 \\
\hline & Male & $26(26)$ & 100 & & & \\
\hline \multirow{5}{*}{ Education } & HS Diploma & $19(19.2)$ & 19.2 & 0.78 & 4.94 & 0.54 \\
\hline & Associate degree & $12(12.1)$ & 31.3 & 0.69 & 4.94 & 0.60 \\
\hline & BA. & $57(57.6)$ & 88.9 & & & \\
\hline & MA. & $7(7.1)$ & 96 & & & \\
\hline & PhD. or above & $4(4)$ & 100 & & & \\
\hline \multirow{5}{*}{ Marital status } & Single & $62(62.6)$ & 62.6 & 2.37 & 4.95 & 0.08 \\
\hline & Married & $34(34.3)$ & 96.9 & 1.13 & 4.94 & 0.35 \\
\hline & Separated & $1(1)$ & 97.9 & & & \\
\hline & Divorced & $2(2.1)$ & 99 & & & \\
\hline & Widowed & $1(1)$ & 100 & & & \\
\hline \multirow{3}{*}{ Infection diseases history } & Personal & $1(1)$ & 1 & 0.44 & 2.96 & 0.65 \\
\hline & Family members & $13(13.1)$ & 14.1 & 2.82 & 2.96 & 0.07 \\
\hline & None & 85 (85.9) & 100 & & & \\
\hline
\end{tabular}

Table 2. Convergent validity coefficients of ERSGPQ with other scales

\begin{tabular}{|c|c|c|c|c|c|c|c|c|c|c|}
\hline Factors & Min. & Max. & Mean $\pm S D$ & Skewness & Kurtosis & 1 & 2 & 3 & 4 & 5 \\
\hline ERSGPQ & 33 & 64 & $50.84 \pm 5.72$ & -0.31 & 0.61 & 1 & & & & \\
\hline aERS & 14 & 30 & $23.72 \pm 2.77$ & -0.51 & 0.95 & $0.84^{* *}$ & 1 & & & \\
\hline mERS & 15 & 35 & $24.42 \pm 3.79$ & -0.16 & -0.02 & $0.75^{* *}$ & $0.33^{* *}$ & 1 & & \\
\hline GPQ & 21 & 44 & $32.71 \pm 5.41$ & -0.18 & -0.49 & $0.52^{* *}$ & $0.61^{* *}$ & 0.17 & 1 & \\
\hline Y-BOCS & 10 & 42 & $20.17 \pm 10.23$ & -0.04 & -0.99 & $0.43 * *$ & $0.52^{* *}$ & 0.13 & 0.50 & 1 \\
\hline
\end{tabular}

ERS-GPQ: Emotion Regulation Strategies About Germophobia Questionnaire; aERS: adaptive Emotion Regulation Strategies; 1mERS: maladaptive Emotion Regulation Strategies; GPQ: Germophobia Questionnaire; Min: Minimum; Max: Maximum; SD: Standard Deviation.

** Coefficients are significant at 0.05 . 
Table 3. Norms of ERS-GPQ

\begin{tabular}{|c|c|c|c|c|c|}
\hline \multicolumn{3}{|c|}{ mERS-GPQ } & \multicolumn{3}{|c|}{ aERS-GPQ } \\
\hline Raw Score & $\%$ & Z Score & Raw Score & $\&$ & Z Score \\
\hline 15 & 1.0 & -2.49 & 14 & 1.0 & -3.51 \\
\hline 17 & 5.1 & -1.96 & 17 & 2.0 & -2.42 \\
\hline 18 & 9.1 & -1.70 & 18 & 5.1 & -2.06 \\
\hline 19 & 11.1 & -1.43 & 19 & 7.1 & -1.70 \\
\hline 20 & 16.2 & -1.17 & 20 & 10.1 & -1.34 \\
\hline 21 & 22.2 & -0.90 & 21 & 16.2 & -0.98 \\
\hline 22 & 27.3 & -0.64 & 22 & 30.3 & -0.62 \\
\hline 23 & 36.4 & -0.38 & 23 & 46.5 & -0.26 \\
\hline 24 & 47.5 & -0.11 & 24 & 59.6 & 0.10 \\
\hline 25 & 59.6 & 0.15 & 25 & 75.8 & 0.46 \\
\hline 26 & 71.7 & 0.42 & 26 & 83.8 & 0.82 \\
\hline 27 & 77.8 & 0.68 & 27 & 92.9 & 1.18 \\
\hline 28 & 86.9 & 0.94 & 28 & 97.0 & 1.55 \\
\hline 29 & 93.9 & 1.21 & 29 & 99.0 & 1.91 \\
\hline 30 & 97.0 & 1.47 & 30 & 100.0 & 2.27 \\
\hline 32 & 99.0 & 2.00 & - & - & - \\
\hline 35 & 100.0 & 2.79 & - & - & - \\
\hline
\end{tabular}

$\mathrm{P}=0.08$; faERS $=1.13, \mathrm{df}=4,95, \mathrm{P}=0.35)$ and history of infectious diseases ( $\mathrm{fmERS}=0.44, \mathrm{df}=2,96, \mathrm{P}=0.65$; faERS $=2.82, \mathrm{df}=2,96, \mathrm{P}=0.07)$. Table 2 presents descriptive findings and the convergent validity of study variables

The minimum, maximum, mean, and standard deviation scores of the explored variables are listed in Table 2. The data of the columns of skewness and kurtosis signified that all of the study variables had normal distributions.

Table 3 presents each score, percentiles, and Z-score of maladaptive and adaptive ERS-GPQ. Based on these distributions, the qualitative ranges were determined as below: the numbers $<17$ in mERS-GPQ were determined as a very low range of mERS-GP, the numbers $17-20$ in

Table 4. Reliabilities of ERS-GPQ and its components, and GPQ

\begin{tabular}{ccccc}
\hline Factors & A & Split-half & Test-retest & Composite Reliability \\
\hline ERS-GPQ & 0.61 & 0.70 & 0.92 & 0.798 \\
aERS & 0.44 & 0.46 & 0.85 & 0.753 \\
mERS & 0.58 & 0.51 & 0.92 & 0.566 \\
GPQ & 0.67 & 071 & 0.95 & - \\
\hline
\end{tabular}


Table 5. Pearson's correlation coefficients and the AVE of ERS and its components

\begin{tabular}{|c|c|c|c|c|}
\hline Factors & 1 & 2 & 3 & 4 \\
\hline ERS-GPQ & 0.815 & & & \\
\hline mERS & 0.757 & 0.659 & & \\
\hline aERS & 0.728 & 0.359 & 0.728 & \\
\hline Trust & 0.181 & 0.068 & 0.180 & 1.000 \\
\hline
\end{tabular}

mERS-GPQ fell in the low range mERS-GP, the numbers 21-26 in mERS-GPQ were classified as the normal range of mERS-GP, the numbers $27-30$ in mERS-GPQ were determined as the high range of mERS-GP, and numbers $>30$ in mERS-GPQ were classified as a very high range of mERS-GP; besides, the numbers $<16$ in aERS-GPQ were determined as a very low range of aERS-GP, the numbers 16-19 in aERS-GPQ were recognized as low range aERS-GP, the numbers 20-28 in aERS-GPQ were reported as the normal range of aERS-
GP, the numbers 29-32 in aERS-GPQ were classified as a high range of aERS-GP, and numbers $>32$ in aERSGPQ were considered as a very high range of aERS-GP.

Table 4 illustrates that ERS-GPQ has acceptable reliability coefficients. The reliability of internal consistency using Cronbach's alpha coefficient was calculated as 0.61 ; the reliability with the split-half method was measured as 0.70 among the items of first and second parts; the test-retest reliability with one-week interval was

Table 6. The results of the confirmatory factor analysis of the ERS-GPQ

\begin{tabular}{|c|c|c|c|c|c|c|}
\hline Cons & Com & Indictors & $\mathbf{R}^{2}$ & $\mathbf{T}$ & CR & AVE \\
\hline \multirow{4}{*}{ mERS-GPQ } & $\mathrm{m}^{1}$ & $\begin{array}{l}\text { 1. I try to hide my worry from others while encountering viruses and bacteria. } \\
\text { 8. I should do everything to cope with the worry of viruses and bacteria. }\end{array}$ & & 4.68 & 0.74 & 0.60 \\
\hline & $\mathrm{m}^{2}$ & $\begin{array}{l}\text { 2. I avoid being in suspicious places to prevent encountering viruses and bac- } \\
\text { teria. } \\
\text { 9. I believe quarantining is the best way of avoiding bacteria and viruses. }\end{array}$ & & 10.63 & 0.82 & 0.69 \\
\hline & $\mathrm{m}^{3}$ & $\begin{array}{l}\text { 6. For a long time after leaving situations where I suspect that there were vi- } \\
\text { ruses and bacteria, I have ruminations about being infected. } \\
\text { 13. I feel I have a serious illness while experiencing the early signs of disease. }\end{array}$ & 0.59 & 11.17 & 0.90 & 0.82 \\
\hline & $\mathrm{m}^{4}$ & $\begin{array}{l}\text { 7. Viruses and bacteria are not so insalubrious, I think. } \\
\text { 14. Some practitioners are exaggerating the dangers of viruses and bacteria. }\end{array}$ & & 1.14 & 0.72 & 0.57 \\
\hline \multirow{4}{*}{ aERS-GPQ } & $a^{1}$ & $\begin{array}{l}\text { 3. In my opinion, hand hygiene is the gold way of countering viruses and bac- } \\
\text { teria. } \\
\text { 10. By using face masks and other personal care products, I protect myself from } \\
\text { viruses. }\end{array}$ & & 11.15 & 0.81 & 0.68 \\
\hline & $a^{2}$ & $\begin{array}{l}\text { 4. Though viruses and bacteria are everywhere, I try to keep a good standard of } \\
\text { hygiene to be less worried about them. } \\
\text { 11. I try to catch up with my unfinished works if I have to stay at home due to } \\
\text { a contagious disease. }\end{array}$ & 0.97 & 15.89 & 0.82 & 0.69 \\
\hline & $a^{3}$ & $\begin{array}{l}\text { 5. With positive self-talk, I try to be calm in bacteria accumulation sites. } \\
\text { 12. In my opinion, viruses and bacteria can be beneficial. }\end{array}$ & & 2.03 & 0.58 & 0.51 \\
\hline & Trust & 15. I believe trust in God and sanctities is a way to counter viruses and bacteria. & & 1.81 & - & - \\
\hline
\end{tabular}

Cons: Constructs; Com: Component; aERS: adaptive Emotion-Regulation Strategies; mERS: maladaptive EmotionRegulation Strategies; $\mathrm{m}^{1}$ : Suppression; $\mathrm{m}^{2}$ : Avoidance; $\mathrm{m}^{3}$ : Rumination; $\mathrm{m}^{4}$ : Denial; $\mathrm{a}^{1}$ : Problem solving; $\mathrm{a}^{2}$ : Acceptance; $\mathrm{a}^{3}$ : Reappraisal. 


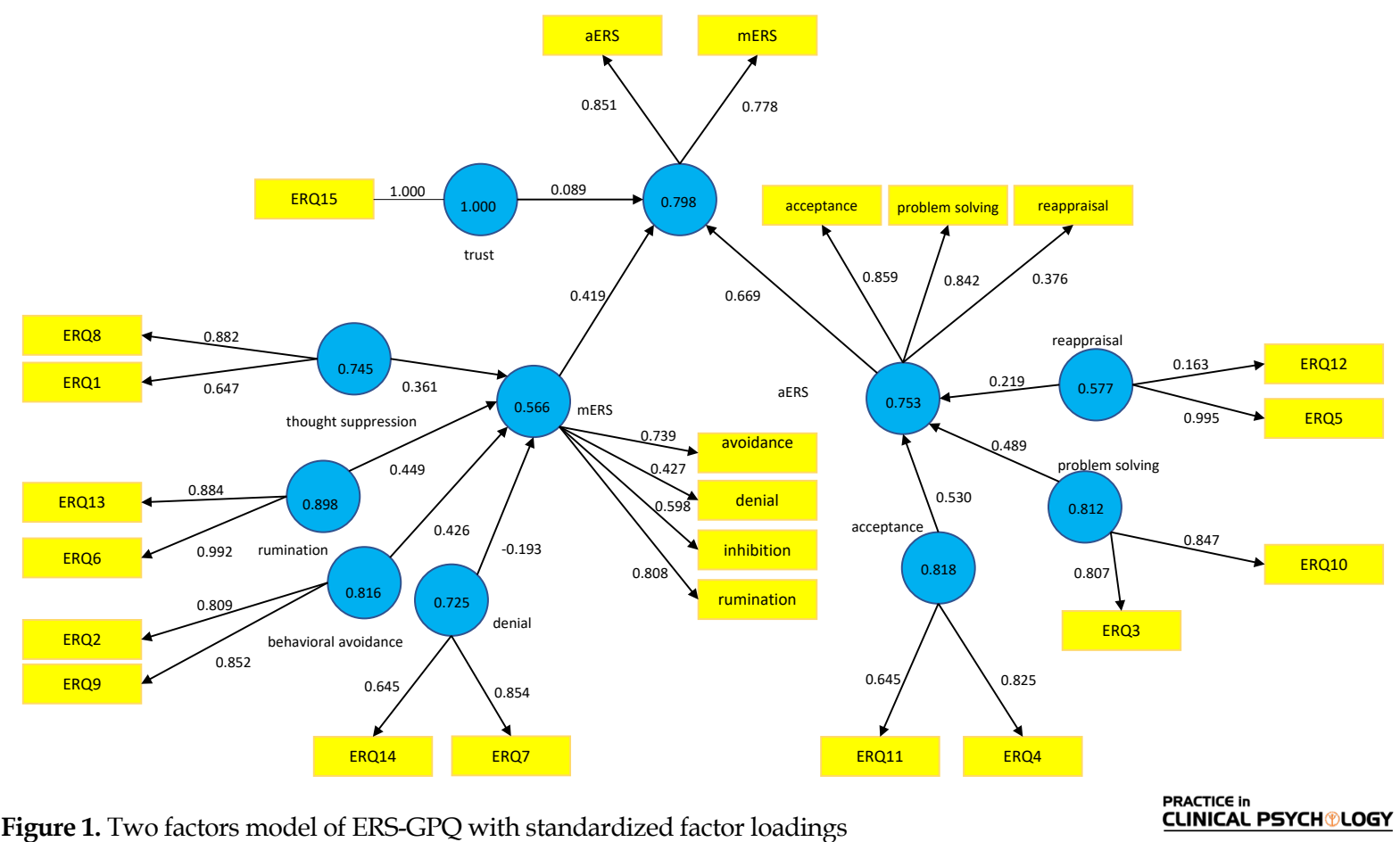

reported to be perfect $(0.92)$. The composite reliability of the component was good and acceptable in adaptive (0.75) and maladaptive (0.57) ERS.

The Content Validity Ratio (CVR) (Lawshe, 1975) of ERS-GPQ was assessed by $8 \mathrm{PhD}$ students of Psychology as panelists. Responses from all panelists were pooled and the number indicating "essential" for each item was determined (Lawshe, 1975). The CVR of all items was $>0.75$. The mean CVR of ERS-GPQ was obtained as 0.84 .

Pearson's correlation matrix of variables is presented in Table 2. Table 2 indicates that the ERS-GPQ had a moderate positive correlation with the GPQ (0.52), and the contamination obsessions checklist of Y-BOCS (0.43). The collected results also indicated that the ERS-GPQ presented positive correlations with its components. Another method for estimating convergent validity is evaluating the significance of standard factor loadings with a value $>0.5$ that leads to a $>1.96$. The correlational matrix of variables and the square root of Average Variance Extracted (AVE) are indicated in Table 5.

Discriminant validity is established if the correlation of all variables of the study has been smaller than the square root of the AVE (Fornell \& Larcker, 1981). The Heterotrait-Monotrait Ratio is another method for evaluating the discriminant validity (Garson, 2016). According to this method, mERS, aERS, and trust are a different component of ERS-GPQ (AVE; HTMT=0.77) (Table 6).
Table 6 demonstrates the results of the confirmatory factor analysis of ERS-GPQ. The first step in the SEM is evaluating the structural model. The structural model is tested when a satisfactory measurement model is obtained. The root mean square residual of the fitness of the model (Figure 1) was good (SRMR=0.18); the suggested SRMR equaled $<0.8$ (Hu \& Bentler, 1999). The squared Euclidean distance $(\mathrm{d}-\mathrm{LS}=9.35)$ is also acceptable, indicating that the model with 2 factors of the present study was acceptable for structural equation models analysis.

Figure 1 illustrates the factor loadings and path coefficients of 2 components of ERS-GPQ. The standard factor loadings of mERS (0.57) and aERS (0.75) were acceptable. The model also indicated the 2 factors structures of ERS-GPQ.

\section{Discussion}

The obtained data were primarily and the present study was a pilot investigation about ERS-GPQ. The relevant results indicated that the ERS-GPQ has acceptable psychometric properties; thus, researchers can use this instrument in epidemic and pandemic virus infections and for assessing the ERSs of germophobia as a specific phobia. These findings suggested that the ERS-GPQ has two factors and one additional question, orderly as adaptive ER, maladaptive ER, and trust. The total score of ERS-GPQ presented a moderate positive correlation with GPQ and the contamination obsessions checklist of 
Y-BOCS; therefore, ERSs about germophobia was a related concept with germophobia and contamination obsessions. Accordingly, these constructs could probably predict each other (Alavizadeh et al., 2020).

The results also indicated gender-wise differences between the levels of aERS-GPQ where women used more adaptive strategies; this was a predictable finding (Gao et al., 2019), and was supported by Zlomke and Hahn (2010), who reported higher levels of acceptance and reappraisal in females (Zlomke \& Hahn, 2010). Moreover, these strategies are two of the three core components of the adaptive styles of ERS. Accepting an active event with negative consequences and reframing of the event, or in other words, attaching meaning to that, can improve optimism and reduce anxiety during such events (Zlomke \& Hahn, 2010). The individual uses the aERS, sometimes as alternatives to mERS, that facilitate ERSs by expressing feelings with more constructive and desirable outcomes (Thompson \& Meyer, 2007). Besides, there were no differences in mERS-GP, among genders, different marital status, different educational levels, and history of infectious diseases. These findings were in line with those of some studies (Bourdon et al., 1988); however, they were inconsistent with those of some other researchers (Fredrikson, Annas, Fischer, \& Wik, 1996). The COVID-19 has become a pandemic; in such circumstances, everyone is stormed by the news, and the media pays particular attention to the issue. Accordingly, it is natural that the level of fear is higher than usual, and that most individuals, regardless of gender, marital status, educational level, or even frequent history of the disease, have more quasi-germophobic experiences; as a result, there were no differences among them (Alavizadeh et al., 2020).

The most important element of ER is aERS, i.e. appropriated with the context of emotions and it can help with the effective reduction of stressful situations (LeBlanc, Essau, \& Ollendick, 2017). Moreover, practitioners can use mERS concerning the etiology and maintenance of germophobia as an anxiety disorder (Sloan et al., 2017).

This study had some limitations. First, the study samples were selected from the general population with relatively high educational levels, and they were not assessed by interviews or self-report. Second, the present study was conducted due to the COVID-19 pandemic, which can be considered as history-graded influences (Berk, 2018). This may increase participants' scores in GPQ. In future investigations, this questionnaire could also be studied in other populations, such as subjects with GAD, OCD, and patients with infectious diseases, as well as other major developmental periods. Finally, it is recommended that exploring these proposed populations be repeated after the pandemic of COVID-19 is over.

\section{Conclusion}

Based on the present research findings, the ERS-GPQ has acceptable and good psychometric properties; researchers can apply the ERS-GPQ as a reliable and valid instrument for assessing ERSs concerning germophobia. It also has some considerations for practitioners in epidemic and pandemic crises, like COVID-19.

\section{Ethical Considerations}

\section{Compliance with ethical guidelines}

This study was approved by the Ethics Committee of Psychology Commission of COVID-19 of the Tehran Province Islamic Azad University (Code: COVID-19/13981201).

\section{Funding}

This research did not receive any grant from funding agencies in the public, commercial, or non-profit sectors.

\section{Authors' contributions}

All authors were equally contributed in preparing this article.

\section{Conflict of interest}

The authors declared no conflicts of interest.

\section{Acknowledgments}

The authors express their gratitude and appreciation to the research participants and all those who contributed to the implementation of this study, especially the presidents of East, Central, South, and North Tehran branches of Islamic Azad University.

\section{References}

Alavizadeh, S. M., Sepahmansour, M., Nokani, M., Entezari, S., Sabet, M., Seirafi, M., et al. (2020). Development and normalization of germophobia questionnaire: A pilot study in Iranian sample (Persian)]. Journal of Arak University Medical Sciences.

Aldao, A., Nolen-Hoeksema, S., \& Schweizer, S. (2010). Emotion-regulation strategies across psychopathology: A meta- 
analytic review. Clinical Psychology Review, 30(2), 217-37. [DOI:10.1016/j.cpr.2009.11.004] [PMID]

Berk, L. E. (2018). Development through the lifespan $\left(7^{\text {th }}\right.$ Ed.). Boston: Pearson. https://books.google.com/ books?id=bvXijwEACAAJ\&dq=

Bhatnagar, P., Shukla, M., \& Pandey, R. (2020). Validating the factor structure of the hindi version of the difficulties in Emotion Regulation Scale. Journal of Psychopathology and Behavioral Assessment, 1-20. [DOI:10.1007/s10862-020-09796-6]

Bourdon, K. H., Boyd, J. H., Rae, D. S., Burns, B. J., Thompson, J. W., \& Locke, B. Z. (1988). Gender differences in phobias: Results of the ECA community survey. Journal of Anxiety Disorders, 2(3), 227-41. [DOI:10.1016/0887-6185(88)90004-7]

Darvish Molla, M., Shirazi, M., \& Nikmanesh, Z. (2018). The role of difficulties in emotion regulation and thought control strategies on pornography use. Practice in Clinical Psychology, 6(2), 119-28. [DOI:10.29252/nirp.jpcp.6.2.119]

Fairholme, C. P., Boisseau, C. L., Ellard, K. K., Ehrenreich, J. T., \& Barlow, D. H. (2010). Emotions, emotion regulation, and psychological treatment: A unified pe rspective. In A. M. Kring \& D. M. Sloan (Eds.), Emotion regulation and psychopathology: a transdiagnostic approach to etiology and treatment (pp. 283-309). New York: The Guilford Press. https://psycnet.apa.org/record/2009-21674-012

Fornell, C., \& Larcker, D. F. (1981). Evaluating structural equation models with unobservable variables and measurement error. Journal of Marketing Research, 18(1), 39-50. [DOI:10.2307/3151312]

Fredrikson, M., Annas, P., Fischer, H., \& Wik, G. (1996). Gender and age differences in the prevalence of specific fears and phobias. Behaviour Research and Therapy, 34(1), 33-9. [DOI:10.1016/0005-7967(95)00048-3]

Gao, Z., Liu, R., \& Ullah, N. (2019, September). A temporal-causal network model for age and gender difference in choice of emotion regulation strategies. Paper presented at International Conference on Computational Collective Intelligence, Hendaye, France, 4-6 September 2019. [DOI:10.1007/978-3-030-28377-3_9]

Garg, A. (2017). A comparative study of cross gender identified males and females on coping strategies, emotion regulation strategies and defense mechanisms [MA. thesis]. Patiala: Thapar University.

Garson, D. (2016). Partial Least Squares: Regression \& Structural Equation Models. North Carolina: Statistical Associates Publishing.

Goodman, W. K., Price, L. H., Rasmussen, S. A., Mazure, C., Fleischmann, R. L., \& Hill, C. L., et al. (1989). The yalebrown obsessive compulsive scale: I. development, use, and reliability. Archives of General Psychiatry, 46(11), 1006-11. [DOI:10.1001/archpsyc.1989.01810110048007] [PMID]

Gross, J. J. (1998). The emerging field of emotion regulation: An integrative review. Review of General Psychology, 2(3), 271-99. [DOI:10.1037/1089-2680.2.3.271]

Gross, J. J., \& Thompson, R. A. (2007). Emotion regulation: Conceptual foundations. In J. J. Gross (Eds.), Handbook of Emotion Regulation (pp. 3-24). New York: The Guilford Press. https:// psycnet.apa.org/record/2013-44085-001
Hair, J. J. F., Hult, G. T. M., Ringle, C. M., \& Sarstedt, M. (2017). A primer on partial Least Squares Structural Equation Modeling (PLS-SEM). Los Angeles: Sage. https://books.google.com/ books?id=Xn-LCwAAQBAJ\&dq=

Hong, F., Tarullo, A., Mercurio, A., Liu, S., Cai, Q., \& MalleyMorrison, K. (2018). Childhood maltreatment and perceived stress in young adults: The role of emotion regulation strategies, self-efficacy, and resilience. Child Abuse $\mathcal{E}$ Neglect, 86, 136-46. [DOI:10.1016/j.chiabu.2018.09.014] [PMID]

Hu, L. T., \& Bentler, P. M. (1999). Cutoff criteria for fit indexes in covariance structure analysis: Conventional criteria versus new alternatives. Structural Equation Modeling: A Multidisciplinary Journal, 6(1), 1-55. [DOI:10.1080/10705519909540118]

Ishikawa, R., Kobori, O., \& Shimizu, E. (2014). Development and validation of the Japanese version of the obsessive-compulsive inventory. BMC Research Notes, 7(1), 306. [DOI:10.1186/17560500-7-306] [PMID] [PMCID]

Lawshe, C. H. (1975). A quantitative approach to content validity. Personnel Psychology, 28(4), 563-75. [DOI:10.1111/j.1744-6570.1975.tb01393.x]

LeBlanc, S., Essau, C. A., \& Ollendick, T. H. (2017). Emotion regulation: An introduction. In C. A. Essau, S. LeBlanc \& T. H. Ollendick (Eds.), Emotion Regulation and Psychopathology in Children and Adolescents (pp. 3-17). Oxford: Oxford University Publishing. [DOI:10.1093/med:psy ch/9780198765844.003.0001]

López-Pina, J. A., Sánchez-Meca, J., López-López, J. A., MarínMartínez, F., Núñez-Núñez, R. M., \& Rosa-Alcázar, A. I., et al. (2015). The Yale-Brown Obsessive Compulsive Scale: A reliability generalization meta-analysis. Assessment, 22(5), 619-28. [DOI:10.1177/1073191114551954] [PMID]

Lotfi, M., Bakhtiyari, M., Asgharnezhad Farid, A. A., \& Amini, M. (2013). The effectiveness of transdiagnostic therapy on emotion regulation strategies of patients with emotional disorders: A randomized clinical trial. Practice in Clinical Psychology, 1(4), 227-32. http:/ /jpcp.uswr.ac.ir/article-1-131-en.html

Melli, G., Avallone, E., Moulding, R., Pinto, A., Micheli, E., \& Carraresi, C. (2015). Validation of the Italian version of the Yale-Brown Obsessive Compulsive Scale-Second Edition (YBOCS-II) in a clinical sample. Comprehensive Psychiatry, 60, 8692. [DOI:10.1016/j.comppsych.2015.03.005] [PMID]

Nolen-Hoeksema, S., Wisco, B. E., \& Lyubomirsky, S. (2008). Rethinking rumination. Perspectives on Psychological Science, 3(5), 400-24. [DOI:10.1111/j.1745-6924.2008.00088.x] [PMID]

Rajezi Esfahani, S., Motaghipour, Y., Kamkari, K., Zahiredin, A., \& Janbozorgi, M. (2012). Reliability and validity of the persian version of the Yale-Brown Obsessive-Compulsive Scale (YBOCS). International Journal of Psychiatry and Clinical Psycholo$g y, 17(4), 297-303$. https://web.b.ebscohost.com/abstract?dir ect $=$ true $\&$ profile $=$ ehost $\&$ scope $=$ site $\&$ authtype $=$ crawler $\& j$ rnl

Roemer, L., \& Orsillo, S. M. (2002). Expanding our conceptualization of and treatment for generalized anxiety disorder: Integrating mindfulness/acceptance-based approaches with existing cognitive-behavioral models. Clinical Psychology: Science and Practice, 9(1), 54-68. [DOI:10.1093/clipsy.9.1.54]

Saad, M., De Medeiros, R., \& Mosini, A. C. (2017). Are we ready for a true biopsychosocial-spiritual model? The many meanings of "spiritual". Medicines, 4(4), 79. [DOI:10.3390/medicines4040079] [PMID] [PMCID] 
Schäfer, J.Ö., Naumann, E., Holmes, E. A., Tuschen-Caffier, B., \& Samson, A. C. (2017). Emotion regulation strategies in depressive and anxiety symptoms in youth: A meta-analytic review. Journal of Youth and Adolescence, 46(2), 261-76. [DOI:10.1007/ s10964-016-0585-0] [PMID]

Sloan, E., Hall, K., Moulding, R., Bryce, S., Mildred, H., \& Staiger, P. K. (2017). Emotion regulation as a transdiagnostic treatment construct across anxiety, depression, substance, eating and borderline personality disorders: A systematic review. Clinical Psychology Review, 57, 141-63. [DOI:10.1016/j. cpr.2017.09.002] [PMID]

Thompson, R. A. (1994). Emotion regulation: A theme in search of definition. Monographs of The Society for Research in Child Development, 59(2-3), 25-52. [DOI:10.1111/j.1540-5834.1994. tb01276.x] [PMID]

Thompson, R. A., \& Meyer, S. (2007). Socialization of emotion regulation: In the family. In J. J. Gross (Ed.), Handbook of Emotion Regulation. New York: The Guilford Press.

Wells, A., \& Cartwright-Hatton, S. (2004). A short form of the metacognitions questionnaire: Properties of the MCQ-30. Behaviour Research and Therapy, 42, 385-96. [DOI:10.1016/S00057967(03)00147-5] [PMID]

World Health Organization (WHO). (1999). Fifty-secondworld health assembly. (A52/24) [Internet]. Retrieved from: https:// apps.who.int/gb/archive/pdf_files/WHA52/ew24.pdf

World Health Organization (WHO). (2020). Coronavirus Disease 2019 (COVID-19): Situation report - 52(52). Geneva: World Health Organization

Zlomke, K. R., \& Hahn, K. S. (2010). Cognitive emotion regulation strategies: Gender differences and associations to worry. Personality and Individual Differences, 48(4), 408-13. [DOI:10.1016/j.paid.2009.11.007] 